\title{
Etanercept as a new therapeutic option for cytokine release syndrome following chimeric antigen receptor T cell therapy
}

\author{
Lina Zhang @, Shuai Wang, Ji Xu, Run Zhang, Han Zhu, Yujie Wu, Liying Zhu, Jianyong Li and Lijuan Chen *i)
}

\begin{abstract}
Cytokine release syndrome (CRS) is the most common toxicity induced by chimeric antigen receptor (CAR) T cell therapy. At present, anti-IL-6 agents including tocilizumab and siltuximab have been applied in the treatment of CRS. However, tocilizumab and siltuximab are expensive and some patients fail to respond to anti-IL-6 therapy, which urges the need for new drugs. In clinical practice, we found some patients with multiple myeloma developed markedly increased levels of tumor necrosis factor (TNF)- a during the CRS period after anti-BCMA CART cell infusion. Here we present the successful use of TNF-a inhibitor (etanercept) to cure CRS in three patients. The introduction of etanercept did not alter patients' response to CART cell therapy and no adverse event was observed directly related to the administration of etanercept. Furthermore, in vitro experiments confirmed that etanercept did not affect the proliferation and effector function of CART cells. Our results indicate that etanercept could be considered as a treatment option for CRS in patients with significantly elevated TNF-a levels.
\end{abstract}

Keywords: Tumor necrosis factor - $a$, Etanercept, Cytokine release syndrome, Chimeric antigen receptor T cell therapy, Multiple myeloma

To the Editor,

Over the past decade, chimeric antigen receptor (CAR) $\mathrm{T}$ cell therapy has brought hope to patients with relapsed/ refractory multiple myeloma (R/R MM), but toxicities such as cytokine release syndrome (CRS) have emerged as new challenges [1]. The CARTOX Working Group and the NCCN guidelines both recommend anti-IL-6 agents (tocilizumab and siltuximab) and corticosteroids as treatments for CRS [2, 3]. However, improved treatment for CRS remains an unmet clinical need, because the existing

*Correspondence: chenljb@126.com

Department of Hematology, the First Affiliated Hospital of Nanjing Medical University, Jiangsu Province Hospital, Collaborative Innovation

Center for Cancer Personalized Medicine, Nanjing 210029, China drugs are not always sufficiently effective. IL-1R antagonist (anakinra) [4], GM-CSF inhibition (lenzilumab) [5], and plasma exchange [6] have been reported as managements for CRS. Moreover, Lee, et al. [7]. successfully used TNF- $\alpha$ inhibitor (etanercept) to treat grade 3 CRS in a 19-year-old female patient with relapsed Hodgkin lymphoma. This was, however, not sufficient to confirm the therapeutic effects of etanercept because she was treated with etanercept and methylprednisolone simultaneously.

Eight patients with R/R MM were enrolled in our study and received LCAR-B38M (anti-BCMA CAR T cells) infusion from March 2017 to March 2020. The clinical characteristics of patients and details of CAR T cell therapy are summarized in Table 1. Fifty-four cytokines were monitored before and after LCAR-B38M infusion by Luminex in all the patients and the detailed results are 


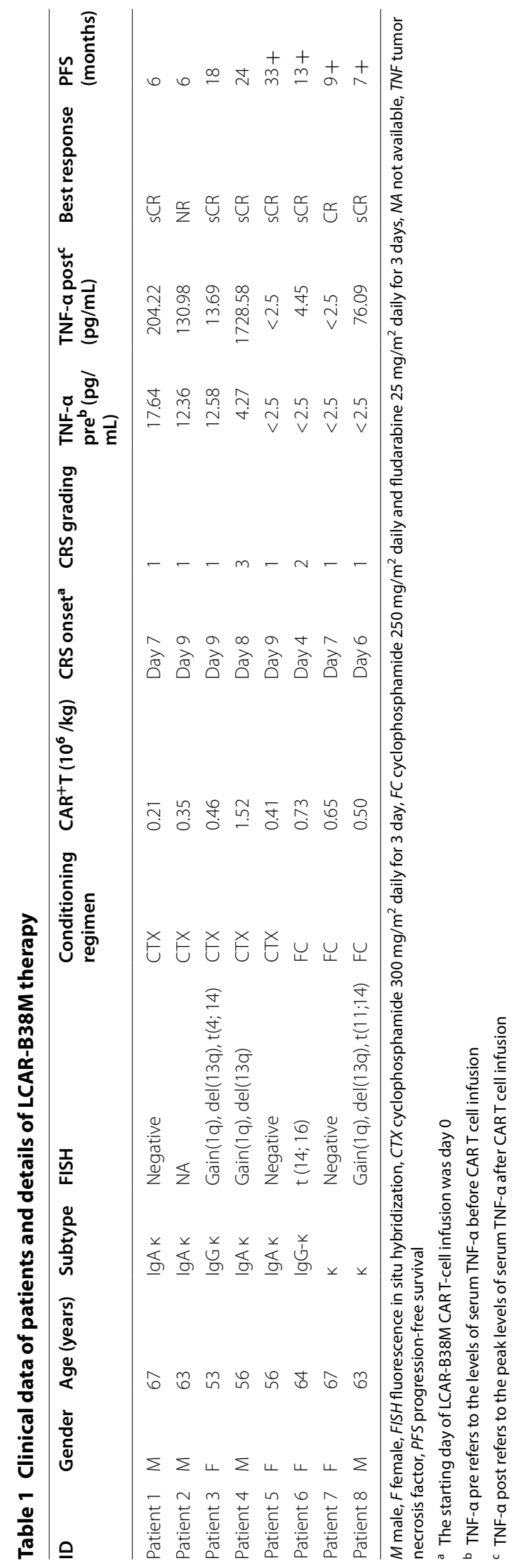


reported in Additional file 1: Table S1. We found a significant increase in IL-6, TNF- $\alpha$, IL-10 and TGF- $\alpha$ during the clinical CRS period. More interestingly, Patient 1, Patient 4 and Patient 8 exhibited markedly elevated levels of TNF- $\alpha$, which was the reason for using etanercept to treat CRS in these patients.

Patient 1 presented with a fever of up to $39.0^{\circ} \mathrm{C}$ on day 7 and was treated with paracetamol. However, his body temperature reached $39.4^{\circ} \mathrm{C}$ on the second day and he received a subcutaneous injection of etanercept $(25 \mathrm{mg})$ on day 8 (Fig. 1b). Subsequently, his temperature gradually returned to normal. Patient 4 presented with fever on day 8 and experienced neutropenia (grade 3), increased serum aspartate aminotransferase (grade 3 ), hypotension (grade 3) and arthralgia (grade 3). On days 10 and 11, he received intravenous tocilizumab (240 $\mathrm{mg}$ on day 10 and $240 \mathrm{mg}$ twice a day on day 11) and additional supportive care. However, his symptoms did not improve despite the repeated use of tocilizumab; therefore, we used etanercept $(50 \mathrm{mg})$ on day 11 (Fig. 1c). He responded promptly to this treatment and recovery occurred gradually. Patient 8 developed grade 1 CRS on day 6 , which was managed with antipyretics. However, he again developed a fever of up to $38.5^{\circ} \mathrm{C}$ on day 14 . No evidence of severe infection was present. We considered that the reemergence of fever was also associated with CRS because the serum IL-6 level also increased. Notably, his serum TNF- $\alpha$ level was more than 30 times higher than the baseline. Therefore, etanercept $(25 \mathrm{mg}$ ) was given on day 17 and symptoms did not recur again (Fig. 1d).

To our knowledge, this study is the first attempt to use etanercept monotherapy to treat CRS following CAR T cell therapy. All three patients achieved sCR and we did not observe adverse events directly related to administration of etanercept. Our findings were further supported by in vitro experiments demonstrating that etanercept did not affect CAR T cell proliferation or killing effects on MM cells (Fig. 1e-g). Specific details were provided in Additional file 1.

TNF- $\alpha$, a major proinflammatory cytokine, is secreted by activated macrophages, monocytes and lymphocytes [8]. Significantly elevated levels of TNF- $\alpha$ have been reported in patients with acute lymphoblastic leukemia who received anti-CD19 CAR T cell infusion [9], which was consistent with our results. Furthermore, the peak level of TNF- $\alpha$ in the serum of patients was considered associated with the severity of CRS [9]. These findings suggest that TNF- $\alpha$ might play an important role in CRS. Etanercept has been widely used in the treatment of rheumatoid arthritis and its efficacy and safety are well established [10]. We suggest that etanercept can be used to manage CRS associated with CAR T cell therapy, and

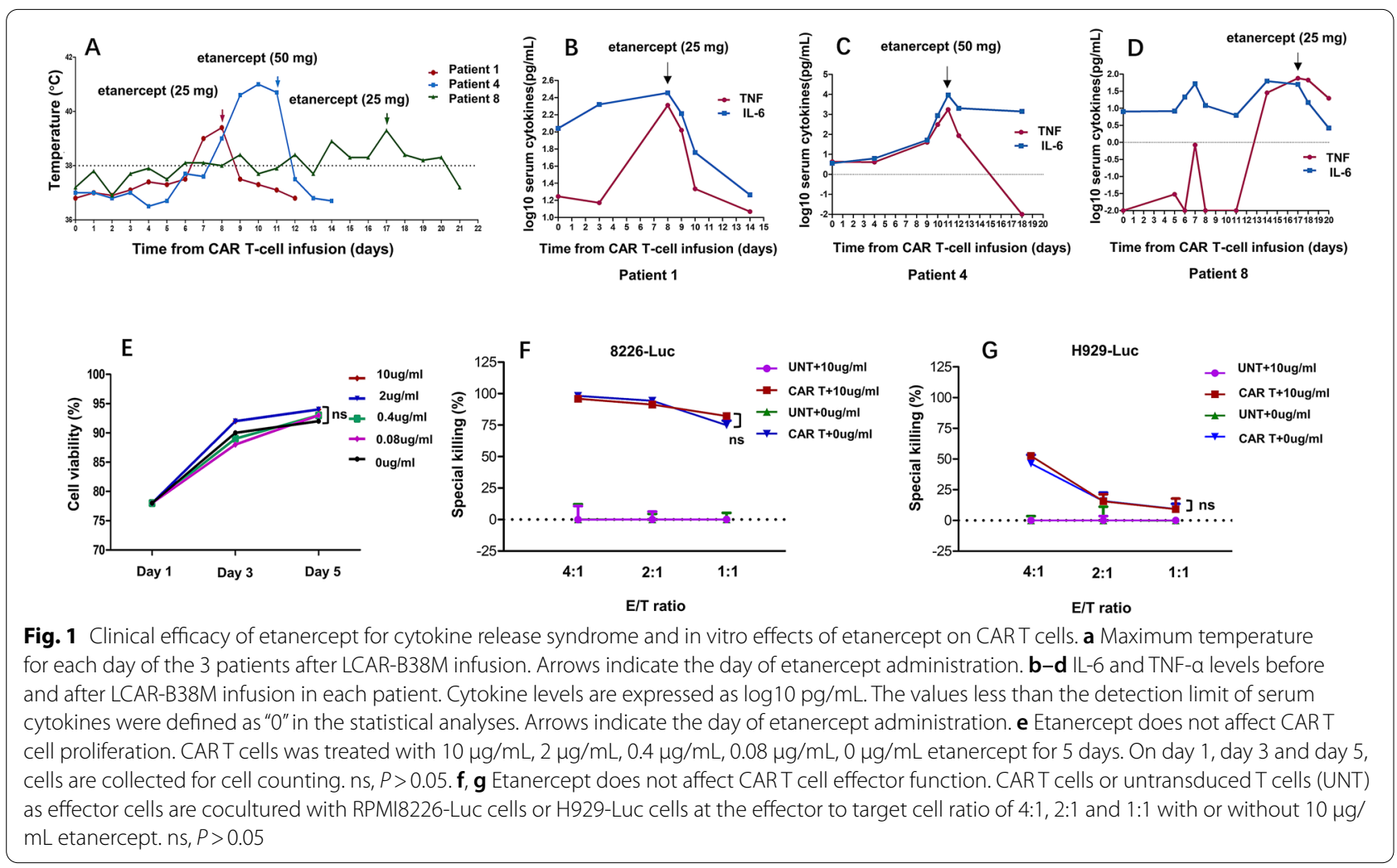


especially recommend for patients suffering from a rapid elevation of TNF- $\alpha$. Of course, further studies are needed to confirm this suggestion.

\section{Supplementary Information}

The online version contains supplementary material available at https://doi. org/10.1186/s40164-021-00209-2.

Additional file 1. Additional tables.

\section{Abbreviations}

CAR: Chimeric antigen receptor; MM: Multiple myeloma; R/R: Relapsed/ refractory; CRS: Cytokine release syndrome; TNF: Tumor necrosis factor; SCR: Stringent complete response; BCMA: B cell maturation antigen..

\section{Acknowledgements}

We thank the patients and their families for participating in this research.

\section{Authors' contributions}

Conception and design: LC, JL. Development of methodology: LC, LZ. Acquisition of data: SW, JX, RZ, HZ, YW, LZ, Analysis and interpretation of data: LZ, SW, $J X, R Z, H Z, Y W, L Z$. Writing, review, and/or revision of the manuscript: LC, LZ. Administrative, technical, or material support: YW, LZ, JL. Study supervision: LC. All authors read and approved the final manuscript.

\section{Funding}

This work was supported by grants from the National Natural Science Foundation of China (No.81670199, No.81720108002), National Science and Technology Major Project (2018ZX09734007), and Jiangsu Province's Medical Elite Program (ZDRCA2016015).

\section{Availability of data and materials}

Data sharing is not applicable to our study.

\section{Ethics approval and consent to participate}

This study was approved by the institutional review boards of the First Affiliated Hospital of Nanjing Medical University Ethics Committee. Informed consent was obtained from all patients for the treatment protocol.

\section{Consent for publication}

Informed consent for research and publication from the patients was obtained.

\section{Competing interests}

The authors declare that they have no competing interests.
Received: 16 November 2020 Accepted: 9 February 2021

Published online: 19 February 2021

\section{References}

1. Liu D, Zhao J. Cytokine release syndrome: grading, modeling, and new therapy. J Hematol Oncol. 2018;11:121.

2. Neelapu SS, Tummala S, Kebriaei P, Wierda W, Gutierrez C, Locke FL, et al. Chimeric antigen receptor T-cell therapy - assessment and management of toxicities. Nat Rev Clin Oncol. 2018;15:47-62.

3. Thompson JA, Schneider BJ, Brahmer J, Andrews S, Armand P, Bhatia S, et al. NCCN Guidelines Insights: Management of Immunotherapy-Related Toxicities, Version 1.2020. J Natl Compr Canc Netw. 2020;18:230-41.

4. Jatiani SS, Aleman A, Madduri D, Chari A, Cho HJ, Richard S, et al. Myeloma CAR-T CRS Management With IL-1R Antagonist Anakinra. Clin Lymphoma Myeloma Leuk. 2020;20:632-6.

5. Sterner RM, Sakemura R, Cox MJ, Yang N, Khadka RH, Forsman CL, et al. GM-CSF inhibition reduces cytokine release syndrome and neuroinflammation but enhances CAR-T cell function in xenografts. Blood. 2019;133:697-709.

6. Xiao X, He X, Li Q, Zhang H, Meng J, Jiang Y, et al. Plasma Exchange Can Be an Alternative Therapeutic Modality for Severe Cytokine Release Syndrome after Chimeric Antigen Receptor-T Cell Infusion: A Case Report. Clin Cancer Res. 2019;25:29-34.

7. Lee DW, Gardner R, Porter DL, Louis CU, Ahmed N, Jensen M, et al. Current concepts in the diagnosis and management of cytokine release syndrome. Blood. 2014;124:188-95.

8. Mitoma H, Horiuchi T, Tsukamoto H, Ueda N. Molecular mechanisms of action of anti-TNF- $a$ agents - Comparison among therapeutic TNF-a antagonists. Cytokine. 2018;101:56-63.

9. Wang J, Mou N, Yang Z, Li Q, Jiang Y, Meng J, et al. Efficacy and safety of humanized anti-CD19-CAR-T therapy following intensive lymphodepleting chemotherapy for refractory/relapsed B acute lymphoblastic leukaemia. Br J Haematol. 2020;191:212-22.

10. Tracey D, Klareskog L, Sasso EH, Salfeld JG, Tak PP. Tumor necrosis factor antagonist mechanisms of action: a comprehensive review. Pharmacol Ther. 2008;117: 244-79.

\section{Publisher's Note}

Springer Nature remains neutral with regard to jurisdictional claims in published maps and institutional affiliations.
Ready to submit your research? Choose BMC and benefit from:

- fast, convenient online submission

- thorough peer review by experienced researchers in your field

- rapid publication on acceptance

- support for research data, including large and complex data types

- gold Open Access which fosters wider collaboration and increased citations

- maximum visibility for your research: over 100M website views per year

At BMC, research is always in progress.

Learn more biomedcentral.com/submissions 